\title{
Negotiating Conflict: A Discussion of Interactive Documentary as Constructive Storytelling in Societies Emerging from Conflict
}

\author{
JAMIE MCROBERTS, Queen's University Belfast
}

\begin{abstract}
Storytelling is often cited as an important device for recovery and transformation in societies emerging from war and conflict. When official storytelling processes are problematic or non-existent, the process of addressing a conflicted past is often tackled creatively. Existing forms of unofficial storytelling have been identified as therapeutic and empowering but also as having limitations. The potential of an emerging form of narrative representation known as interactive documentary has been used to help negotiate themes of conflict, but remains under-researched. This paper explores four modes of interactivity (Gaudenzi 2013) and applies key factors in Jessica Senehi's (2002) constructive storytelling to explore essential commonalities and differences between the two. The paper argues that interactive documentary has the potential to offer a unique contribution to the negotiation of complex and contested narratives of conflict but may contain limitations depending on how technologies are applied to realise the aims of constructive storytelling.
\end{abstract}

\section{KEYWORDS}

Conflict; Documentary; Interactive; Storytelling; Technology 


\section{Introduction: Storytelling in Post-Conflict Societies}

Storytelling in its purest form is interested in the age-old tradition of face-to-face dialogue, a simple process of 'someone telling someone else that something happened' (Smith 1981, 228). For the purposes of this inquiry, a more expansive understanding of storytelling has been adopted, where the story is contextually related to experiences of war and conflict, and the telling of the story has been recorded audiovisually and negotiated through a media form. Storytelling is seen as integral to societies emerging from political violence and conflict, and has thus emerged as one of the most cited means of offering transformation within such transitional societies (Mairs 2013, 22). In such contexts, storytelling practices are encouraged or instituted specifically with the aim of reducing inter-group conflicts in order to enhance peace building and reconciliation between adversaries. For example, in Northern Ireland, the Consultative Group on the Past, established in order to find a way to deal with the legacy of the "Troubles' ${ }^{1}$ presented a report clearly stating that 'storytelling is an important feature of any conflict transformation process' (Report on the Consultative Group on the Past 2009, 32). This is a sentiment that has also been echoed in discussions of other transitional societies, most notably, in relation to the Truth and Reconciliation Commission (TRC), which was established in 1995 to deal with South Africa's Apartheid years. Storytelling, within the TRC context, was used very specifically as a form of face-to-face restorative justice, and as a means of managing victims' trauma and dealing with victims and perpetrators in a way that enabled society to move on from the conflict (Boraine 1999).

All cultures and societies possess their own stories or narratives about their past and their present, and telling one's story has been shown to be critical to recovery for those who have undergone personal or social trauma. Dan McAdams (1993) argues that through narratives, a culture's 'stories create a shared history, linking people in time and event as actors, tellers, and audience' (25-6). The forms that storytelling take in post-conflict situations can vary but, common to most forms, is 'testimony giving.' Testimony giving is a process in which victims of war and violence convey stories that can range from first-hand experiences of pain and trauma to community narratives of survival and human resistance (Hackett and Rolston 2009, 355). The rationale promoted for such storytelling in post-conflict societies is that reflection on the past is necessary, even though it may be painful, because a divided society can only 'build a shared future from its divided past' (Tutu 2003, 5) by people listening to one another. Storytelling, it is argued, can raise awareness of differing sides' understanding of the conflict. It thereby effectively offers possibilities for empathic understandings or compromise that can potentially reconcile divided elements of a society and help with transitions to peaceful political settlements (Gormally \& McEvoy 2009).

There remains a complex relationship between truth, memory and narrative or storytelling in post-conflict societies that raises a host of questions about whose voice gets heard?; whose story gets recognition?; in which context?; through what types of medium? And, how, if at all, does any transformation occur through the process of storytelling? Endeavours to answer such complex questions have been attempted by means of numerous forms of storytelling, both through official and unofficial

\footnotetext{
${ }^{1}$ The thirty-year conflicts over the constitutional status of Northern Ireland.
} 
channels. Official or formal processes, including state and public bodies discourses and media representations, can be deemed problematic or propagandistic, as they often reduce complex and multi-layered, conflictual narratives into a single or dominant narrative that can exclude, misrepresent or marginalise certain groups (Hackett and Rolston 2009, 358). At other times, official channels may be nonexistent, as is the case in Northern Ireland, where the main political parties strive without success to reach any consensus on how to deal with the legacy of the past (Mairs 2013, 6) or to facilitate any shared narratives for the future. In such cases, unofficial storytelling projects have emerged that challenge authorised, hegemonic narratives and offer opportunities for 'voice' when formal channels do not present themselves. Unofficial mediations of storytelling have manifested in a range of forms such as fiction, documentary film, oral history, performance, community-based initiatives and cross-community archives. Each of these forms offers differing opportunities for story-telling, and poststorytelling, where the stories are listened to or engaged with, by an audience, and through which people encounter and potentially better understand each other's history, culture, politics and hopes for the future.

Challenges associated with story-telling in post-conflict contexts have also been widely observed, evident in an ever-present debate (Felman and Laub 1992; Jelin 2003; Rogers et al. 2004; McLaughlin 2010; Mairs 2013; Moloney 2014) on whether the process of revisiting and externalising trauma may have the potential to both 'heal trauma and open old wounds' (Aguiar 2015, 20). Toome (2000), for example, talks of the pathologisation of trauma in Timor Leste, where local communities, in her view:

....are expected to open their wounds to reveal their trauma or confess their sins, to appreciate the soothing salve of therapeutic reconciliation, and to passively accept the failure of the state and international community to deliver on their expectations... (28)

Another overarching drawback in relation to storytelling occurs more obviously in poststorytelling where concerns are raised about how testimonies are mediated and represented to audiences. For instance, although attempting to empower the participant, community-based oral history archives can be problematic, where, the stories are often unable to transcend the community from which they were produced, and can lead to what is described as a 'ghettoization of memory' (Hackett and Rolston 2009, 369). In such instances of social or geographical segregation, those outside or antagonistic to the community often do not hold the same affinity or may dismiss any emergent narratives as too biased or exclusionary, and thus, there is little opportunity for mutual understanding. These scenarios can, however, benefit from drawing on cross-community oral history archives, which according to Moloney (2014), have the potential to 'facilitate relationship building and create opportunities to explore both the consequences and causes of the conflict' (17).

The power of film is also well recognised as a means to mediate and represent narratives in post-conflict societies. However, in relation to the representation of victims' testimonies via conventional documentary film, problems can arise from the 'inevitable power imbalance in the production of audio-visual stories' (Mairs and McLaughlin 2012, 33). Traditional documentary, in certain instances, can too readily singularise complex narratives due to its tendency to conform to the archetypal organisation of film (McKee 1997). Editorial decisions over the selection and 
exclusion of certain individual or group perspectives can have major implications over the balance of the narrative in a post-conflict situation. Further, editorial decisions over inclusion/exclusion of events based on newsworthiness or of audience retention and aesthetical choices, as for example when using cross cutting for dramatic effect, may also divert the film from offering transformational opportunities.

More recently, collaborative filmmaking methodologies have been proposed and developed in order to try to shift agency from the filmmaker towards the participant. $^{2}$ With the onset of the digital age, and its vast reservoirs of storage media and instantaneous access, designers of visual communication have begun to innovate ways in which stories can be told, and more importantly, experienced by audiences - all of which have potential application for post-conflict resolution. One of the most specific and rapidly evolving media forms is interactive documentary. Challenging to define, interactive documentary has been referred to as 'interactive online/offline applications, carried out with the intention to represent reality' (Galloway et al. 2007, 330). Galloway et al.'s definition implicates components now commonly understood by the terminology; that 'an interactive documentary needs to use a digital support, and be interactive' (Gaudenzi 2013, 26). What remains unclear is what is meant by interactive or interactivity. This paper argues that the inclusion of the term representation appears misleading, and perhaps outdated, as it implies interaction solely as an interpretation of the film text, akin to early understandings of how linear documentary was received. Negotiation with reality has since been preferred to representation, since Stella Bruzzi's (2000) proposal that documentary takes place 'between reality on one hand and image, interpretation and bias on the other' (4). Here, interactivity is seen as an extension of the concept of negotiation given that the audience is engaged in a new way, where the 'viewer' is transformed into an active agent who must negotiate cognitively and physically with the digital artefact towards the co-creation of meaning. Creators of interactive documentary have come to recognise their ability to engage audiences in a user-centric process, where emotion, morality and understandings are questioned through their negotiation of the media and, in this case, in relation to war and conflict narratives. However, given the relative infancy of interactive documentary, it is a form that remains largely under-theorised and under-researched, especially in relation to post-conflict application.

\section{Constructive Storytelling and Modes Of Interactive Documentary}

The recognisable, paradigmatic shift in the user's relationship to the text highlights a connection to Senehi's (2002) concept of constructive storytelling in processes of political and intergroup conflicts and their transformation. Constructive storytelling she defines as:

...inclusive and fosters collaborative power and mutual recognition; creates opportunities for openness, dialogue, and insight; a means to bring issues to consciousness (45).

\footnotetext{
${ }^{2}$ Preferred term to that of interviewee, subject or testimony-giver as 'participant' hints at a more mutual, collaborative engagement.
} 
She counterpoises this with destructive storytelling where, in societies emerging from violence, such a process is generally met with suspicion and repudiation, due to 'exclusionary practices, a lack of mutual recognition, dishonesty and a lack of awareness' (Senehi 2002, 45). These characteristics are underpinned by a coercive power struggle, which she describes as being a case of 'power over' as opposed to 'power with' the participant (ibid). Senehi proceeds to identify seven factors (viz. knowledge, identity, socialization and education, emotion, morality, memory and time and geographic space) considered essential for constructive storytelling in relation to transforming conflicts. Such a framing opens a more critical debate on the use of interactive documentary and its relationship to constructive storytelling for transformative purposes.

This inquiry adopts a prime methodological viewpoint based on the study of relevant literature and critical analysis of a range of selected audiovisual exemplars in order to explore the proposed, but largely understudied, relationship between interactive documentary and war and conflict narratives. To strengthen the analysis of this relationship, Sandra Gaudenzi's (2013) taxonomy of four modes of interactive documentary is selected over other existing models (Galloway et al. 2007; Nash 2012) due to its currency and more apt representation of contemporary trends and forms within interactive documentary research and practice. Gaudenzi's taxonomy comprises the hypertext mode, the participatory mode, the experiential mode and the conversational mode. Each mode will be identified and used to frame a particular discussion in relation to constructive storytelling. By means of illustrations of how interactive documentary exemplars have attempted to negotiate various international and inter-group conflicts, the following section examines, in turn, how key factors in constructive storytelling dovetail, or not, with the principles and practices afforded by each of these differing modes of interactivity.

\section{Hypertext Mode: Polyvocality and User Interaction}

The hypertext mode of interactive documentary is described as a closed database in which the user can explore pre-defined narrative routes (Gaudenzi 2013, 50). Seen as a non-fictional, multimedia version of the original text-based medium, it essentially works as nodes of information or data are connected through links. A plethora of types of data can be involved, but in the case of interactive documentary, audiovisual material is most common.

Gaza/Sderot (2008) is a hypertext interactive documentary that centers on the human or everyday impact of the Israeli-Palestinian conflict in two dwellings on either side of the Israel-Gaza security barrier. The project was overseen by Arté3, who established both an Israeli and Palestinian production team to capture short documentaries that follow seven main participants from Gaza, Palestine and seven from Sderot, Israel. The participants represent a range of positions and occupations from the local populace and their stories convey how the conflict has impacted on their daily lives. For example, Abu Khali, an ambulance driver, who

\footnotetext{
3 Association relative à la télévision européenne; a European Television network who specialise in culture and arts-based programs but have recently started to create digital content.
} 
hopes for peace as he negotiates a demanding work-life balance or, Yafa Malka, a hairdresser, who conveys frustration at the lack of future prospects caused by the conflict.

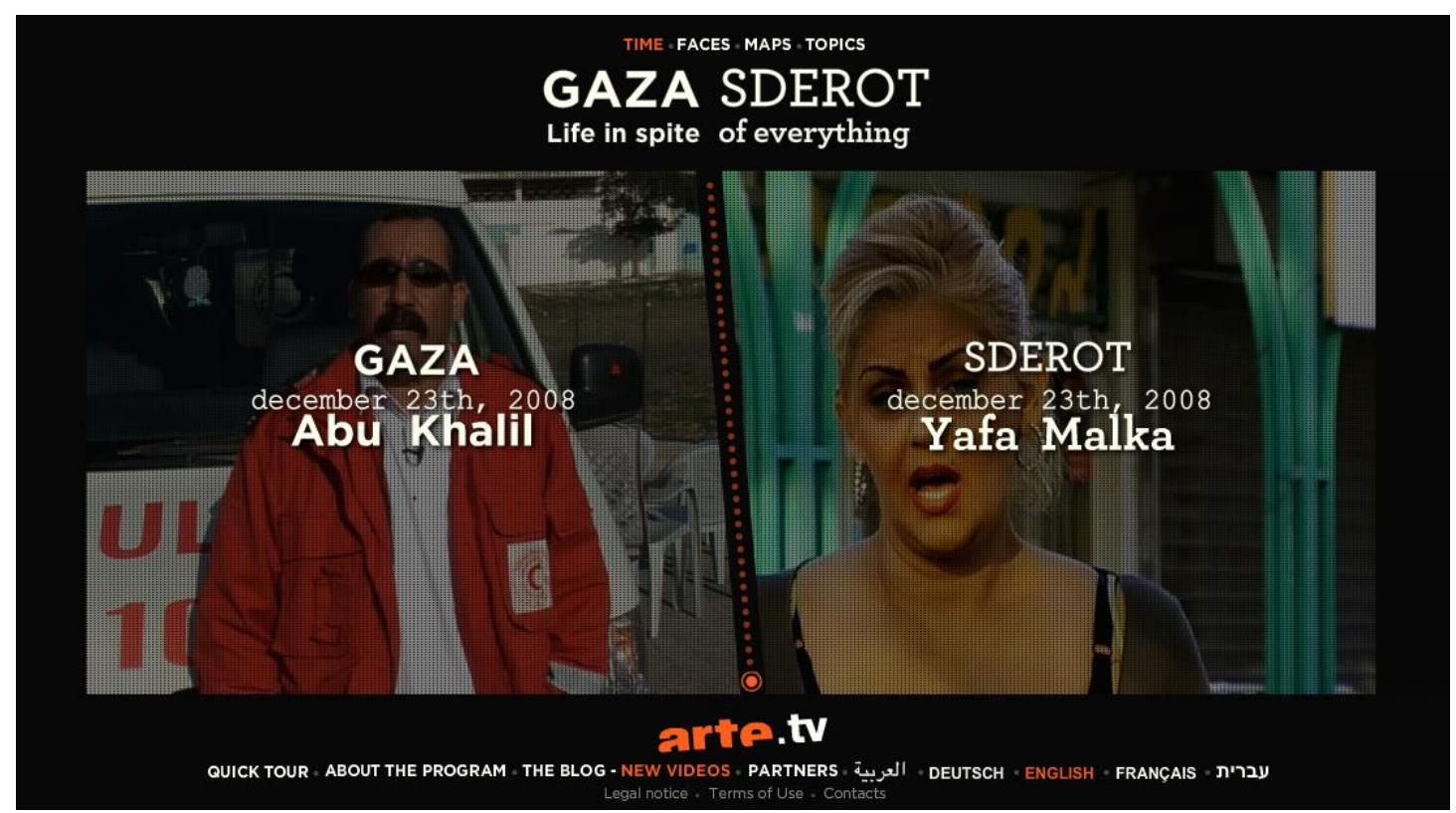

Fig 1 - Gaza Sderot (2008) - Time Interface

The content of Gaza/Sderot and, perhaps the process of recording the audiovisual material is not too dissimilar to that of a traditional documentary film, but the major difference lies in how the material is presented and engaged with by an audience. ${ }^{4}$ The short, recorded documentaries were uploaded on almost consecutive days for a period of two months and were organised around a twodimensional, yet dynamic, interactive interface. The user then has a number of ways in which to interact since the material is categorised by time, faces, maps and themes that are displayed on related sub-interfaces; providing a sense of user agency on how the material can be viewed and in what order. Knowledge and meaning are created within the circular process of interaction as the user navigates and negotiates the myriad different testimonies in an attempt to gain understandings of the conflict. As Senehi (2002) notes, destructive storytelling discourses 'can result in a cultural knowledge or history that may exclude or misrepresent whole groups of people, and collective trauma may remain unacknowledged and therefore unhealed' (47). Gaza/Sderot's multilinear structure affords a polyvocal account in which a wide range of voices can co-exist and none are apparently prioritised over the other. It is understood that Gaza/Sderot may not reflect all strata of those societies, but it provides an example of how an inclusive range of testimonies can be presented within one overarching form.

A paradigm shift in the author-text-audience relationship is also apparent due to the user's involvement with the creation of narrative, which challenges the

\footnotetext{
${ }^{4}$ The term audience incorporates the traditional documentary film 'viewer' and the interactive documentary 'user'.
} 
concept that 'only those in positions of power may have access to producing knowledge' (Senehi 2002, 47). In a web-based interactive documentary project, akin to Gaza/Sderot, any member of the public (provided that they have an internet connection) has the ability to gain knowledge and understandings of the conflict. Furthermore, it creates access to previously unavailable narratives due to lack of contact and internal political narratives in Israel and Palestine.

The mainstay of Gaza/Sderot's interface is the line that divides the screen, visible in Fig 1., which represents the security barrier. Interviewees on the left of the division are from Gaza and those to the right of the division are from Sderot. Moving the cursor to the left will play Abu Khali's interview and moving the cursor to the right will pause Abu Khali's interview and play Yafa Malka's interview. Ingrid Kopp appreciates how the divisional interface forces the user to make comparisons, as '[i]nteractvity isn't just tacked on; it's fundamental to the storytelling' (In Nash 2014, 127). The divisional interface and method of user interaction appears to create a digital manifestation of crosscutting, which has previously been discussed as a limitation of conventional documentary. It is believed that cutting two contrasting perspectives against one another can instill a sense of 'othering' with the audience (Mairs 2013, 43). However, Gaza/Sderot has been realised in such a way that comparisons are drawn on a more humanistic level where the 'personal is political' and the stories can often show us connection, not solely juxtaposition or difference. The principles of constructive storytelling align with Gaza/Sderot in the sense that mutual recognition does not imply a universal understanding of identity, but articulates cultural difference in which a 'paradoxical curiosity' (Lederach 2005, 176) is harnessed, with a desire to engage in dialogue or 'recognise the dignity and experiences of the other' (Senehi 2002, 49).

O'Flynn (2012) questions the interactive meaning-making process in such hypertext documentaries by asserting that they, 'rarely create an emotional resonance with the interactant' (147). Analysing Gaza/Sderot or similar hypertext interactive documentaries from O'Flynn's position would lead to the assumption that the framework by which the material is organised would create meaningless connections or offer no emotional impact from a user perspective. Within the context of conflict storytelling, Senehi (2002) asserts that '[s]tories simultaneously engage mind and heart' (52), suggesting that a self-contained story, free from editing, can stimulate emotional impact. In the case of Gaza/Sderot, the self-contained stories co-exist, and to an extent can maintain their own integrity (Mairs 2013, 18); however the process of user interaction assumes a form of user-led editing - a storytelling device that facilitates the user creating meaning from the database. The process of engaging, editing and uncovering organic connection points may create a different kind of emotional resonance, where the user can, on occasion, feel a sense of moral responsibility as they engage both physically and cognitively with the testimonies. Such processes can stimulate empathy in users as they begin to identify with characters in the story in which constructive storytelling offers the ability to 'create bonds among people during post-conflict peace-building' (Senehi 2002, 53). 


\section{Participatory Mode And User Generated Content}

The past decade has marked the introduction of a vastly different approach to documentary filmmaking; fuelled by the rise of Vernacular Video and fostered in the environment of 'Web 2.0' (Dovey and Rose 2012, 1-2). 'New poetics of collaboration' (ibid, 16) are facilitating participation beyond the process of human-computer interaction enabling the user to have some input towards the making of the artefact, its media or its management and direction (Gaudenzi 2013, 56-7). In projects operating within the participatory mode of interactive documentary, user participation often becomes constitutive of the project itself (De Lusenet 2007; Underberg and Zorn 2013, 47). Within this mode, there are numerous types of participation that can occur, which can range from crowdfunding to the co-creation of the audiovisual content itself. ${ }^{5}$ One of the most prominent forms of participation to emerge within the environment of Web 2.0 is that of user-generated content (UGC).

A common application of UGC occurs where the participatory and hypertext modes intersect. Audiovisual material in this case is gathered on a certain topic and then presented as a database, which often appears as a mosaic structure. 18 Days in Egypt (2011) is an interactive documentary that operates in the participatory mode but represents the audiovisual material as an open hypertext database. Noticing that the history of the Egyptian revolution was being told in real-time through amateur video, photographs and text being distributed through social media channels, the co-creators invited contributions from the Egyptian public to their project built around the group storytelling platform, GroupStream. These social media testimonies offer a counter narrative to that projected by the official channels of the Mubarak regime. 18 Days in Egypt contains accounts that are user-generated, diverse and, at times, contradict or overlap, but co-exist in this mosaic-like database (Fig 2). The project represents a poignant example where people are given an opportunity to tell their story with relative freedom at a time when official storytelling channels were problematic and permitted little agency to the teller. In such instances of digital, grassroots storytelling anyone can contribute their story, creating an inclusive database.

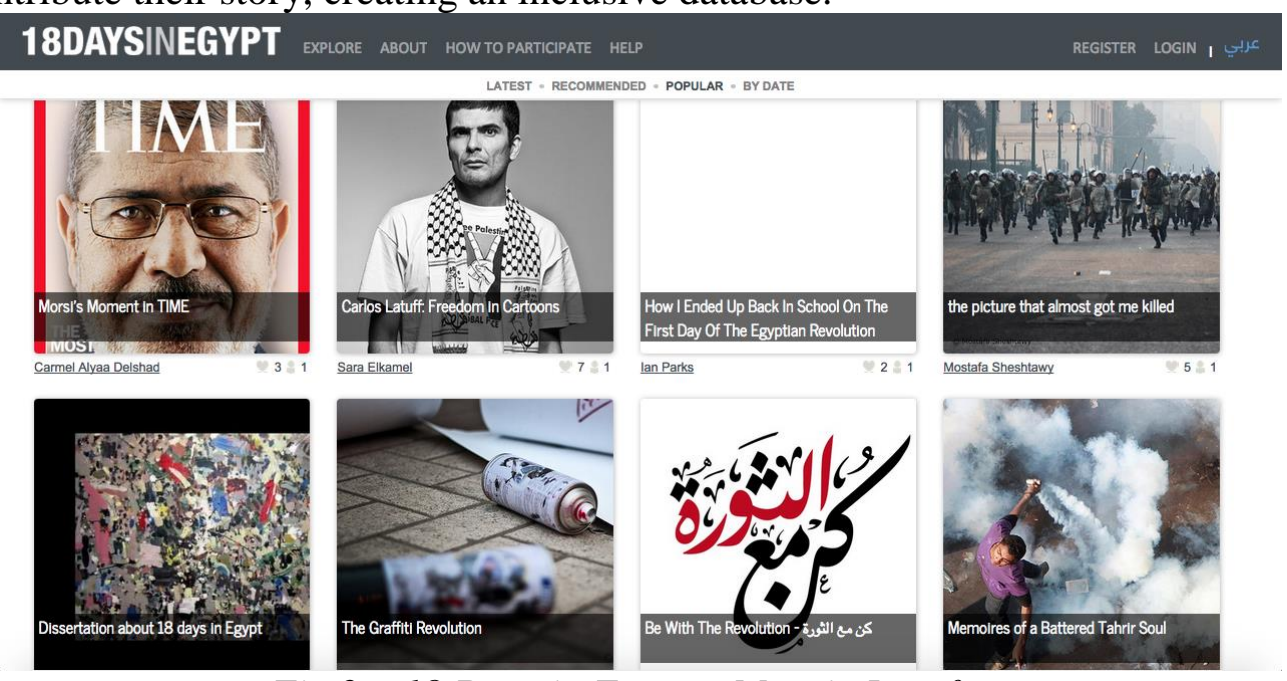

Fig 2-18 Days in Egypt-Mosaic Interface

\footnotetext{
${ }^{5}$ See Gaudenzi (2013) 57-61 for more insight into the seven main approaches to participation.
} 
Within examples of participatory logic, the author-text-audience relationship shifts further in favour of the audience, who are now also the storytellers. The concept of auteur is challenged (Cohen 2012, 327) given that the user submits their story, which remains largely unedited and maintains its own integrity within the larger database. In projects like 18 Days in Egypt, the author's role has been likened to that of a curator, who creates the framework and encourages participation from a wide range in any post-conflict society. The result is a nonlinear form that affords a polyvocal account, and that invites audiences to experience varying viewpoints of the conflict, while simultaneously reflecting upon their own positions (Dovey and Rose 2012).

Interactive documentary projects operating at this intersection of the participatory and hypertext modes have been described as 'evolving databases' due to the potential for content to continuously be added to or amended by its contributors (Gaudenzi 2013, 56). This can facilitate a digital version of poststorytelling, whereby users can directly engage with other storytellers within the participatory documentary community. Where hypertext documentaries have the potential to perhaps transform the user's understanding and knowledge of the conflict on an individual basis, participatory forms, through poststorytelling, mark the potential for the interactive documentary community's worldview to adapt over time - by questioning or responding to others' testimonies. Although such evolutionary potential exists within 18 Days in Egypt, it would be difficult to illustrate the evidence without researching users' experiences.

When discussing emotion in relation to constructive storytelling, Senehi declares the importance of conducting interviews in a comfortable, safe place, the home for example (2002, 52-3). With UGC in participatory interactive documentary, the user is very much in control of their testimony-giving process, since content is often recorded using a webcam or a personal camera/phone and is often recorded in domestic surroundings. While this storytelling conforms to the principle of safe space, an argument could be raised about the security of the web as a place from which to broadcast such testimonies. There is in an apparent vulnerability when placing intimate, personal accounts of trauma in the public domain with no control over who gains access, and what they do with the material. Communities built around such participatory projects may however counter that concern as they create virtual places where 'persons [...] share a common hardship or experience', and 'engage in subjectsubject dialogue, in order to comment upon, interpret, strategize about, and heal from their difficulties' (52-3).

\section{Experiential Mode: Storytelling in Space, Augmented And Virtual}

A recognition exists that geographic space has a strong connection to stories, triggered by the cultural or symbolic influence of the place to the storyteller (Senehi 2002, 55). As McLaughlin (2010) suggests,

...the materiality of the place, its layout, its architecture and its spatial relationships trigger recognition and memory in a way that might not occur if the participant was in another setting (106). 
The beginnings of a digital manifestation of 'cultural landscapes' (Dawson 2005, 155) are evident in the experiential mode of interactive documentary, which occurs when layers of data are added to a physical space (Gaudenzi 2013, 63). Geo-location and mobile technologies are incorporated to facilitate a user's navigation and interaction within an augmented version of the physical world. Interactive documentary examples of conflictual narratives that operate within the experiential mode are not yet available.

Streets of Belfast, an app, developed by Belfast-based theatrical company, Kabosh, offers a relative example of how similar technologies have been applied in the portrayal of narratives relating to intergroup conflict. The app functions primarily as a 'walking tour', in which users can uncover data attached to geo-locations, described as 'tour points' along the Falls Road and Shankill Road; areas that were trigger points in the Northern Irish 'Troubles'. The majority of the data presented could be described as non-fictional, offered in a variety of formats (photographs, video, text and audio). In addition, the project contains theatrical dramatisations of events inspired by 'true stories' or folklore, but which ultimately, open up debates about truth claims lying beyond the scope of this paper. The various forms of data are reinforced by audio and video interviews with two local tour guides, expressing their understandings of the neighbouring, yet segregated, streets.

The resulting narrative offers 'different cultural worldviews' on either side of the International Peace Wall, that separate these two locations and which are deeply embedded in geography and identity (Senehi, 2002, 55). This perhaps runs counter to Senehi's requirement of geographic space in constructive storytelling - that it should offer segregated communities opportunities to 'craft shared narratives' in which 'they may simultaneously develop shared identities and a cooperative vision of the place" (56). The concept of storytelling, as a way to reinterpret contested space, is thus vastly underexplored. As of yet, examples of constructive storytelling within the experiential mode remain elusive, perhaps due to legal and ethical concerns, but possibly also due to the segregation of physical space that is so characteristic of many post-conflict societies.

\section{Conversational Mode: Immersivity and Emotion}

The conversational mode of interactive documentary contains multiple similarities to the experiential mode due to the overlapping themes of embodied experience. Within the conversational mode, interactivity occurs in a virtually simulated or reconstructed world (rather than an augmented physical world) where 'the user is to feel free to improvise movement at any moment and the software has to smoothly respond to such decisions' (Gaudenzi 2013, 40). The conversational mode is often compared to the field of docu-games, due to its commonality with videogame style navigation, but it should be noted that the conversational mode can occur without any major gamification of the experience. This mode is primarily characterised by the user's spatial immersion and traversal of virtual space, in which they are positioned as a unique observer, rather than a player with tasks or missions to complete. The 'conversation' is derived from the two-way process between the user and the software, where the software must respond to the user's input. This creates a real-time 
quality where the user's improvisation of a certain movement, a right turn for example, results in an instantaneous replication of the movement on the screen or head-mounted display.

Interestingly, the conversational mode is more thoroughly explored in relation to narratives of war and conflict than the experiential mode. Former journalist, Nonny de la Peña is regarded as a pioneer within the field of virtual reality, due to her experimental projects using virtual and immersive technologies to negotiate contentious social and political narratives. She coined the term 'immersive journalism', a form that allows users a first-person experience of events present in news and media. De la Peña's projects include Use of Force (2013) that immerses the audience in the moment that migrant Anastasio Hernandez Rojas was assaulted and beaten by border patrol agents after trying to sneak back across the US border and Project Syria (2014) that puts the audience 'on scene' to experience the plight of Syrian child victims in the civil war. However, it is the more primitive Gone Gitmo (2007), which offers the most relevant example. In this project, Guantánamo Bay, one of the world's most controversial prisoner of war camps, has been virtually reconstructed. The user can navigate the prison, access transcripts from detainee interrogation logs and clips from de la Peña's (2004) linear documentary Unconstitutional about Guantánamo.

Throughout this virtual experience, the user also witnesses and is exposed to reconstructions of forceful interrogation and brutality. Affordance of first-person navigation in the project, in which users can explore and experience the sights, sounds and perhaps emotions evoked by the place, lead to what is often referred to as a 'sense of presence' (Gaudenzi 2013, 44). This creates meaning through a unique perspective that inherently contrasts the more traditional forms of audiovisual storytelling (Dovey and Kennedy 2006; Gaudenzi 2013). The aim is not necessarily to bring the audience 'closer to the truth' (Willis 2003, 23) but to offer them different and perhaps more empathic perspectives. As the amount of audiovisual information available today has led to the growing concern that audiences may be becoming indifferent to topics involving trauma, conflict and human suffering (Kinnick et al 1996; O'Neill \& Nicholson-Cole 2009), such forms of immersion may reinstitute audiences' empathic responses to such narratives (De la Peña et al. 2010, 298).

The unique perspective offered by the first-person, immersive qualities of Gone Gitmo, and similar conversational interactive documentaries, evoke emotion and contemplations of morality from the user in relation to the negotiated narratives of conflict. Henderson (1996) recognises storytelling's ability to touch the heart as a potent means to stimulate social change (Senehi 2002, 53). At the same time storytelling may have the ability to fuel powerful emotions of fear, suspicion, anger and grief, prevalent in intergroup conflicts, depending on how the narratives are poised or presented (Senehi 2002, 52). On one hand, Gone Gitmo's immersion of the user inside Guantanamo Bay to bear witness to prisoner brutality, may evoke empathic and emotional responses that questions the perceived violation of human rights. On the other, the user is denied access to any other perspectives, which may lead to a process of 'demonizing the enemy' (Senehi 2002, 53). Framing such a powerful, yet conflicting narrative 'can make ideology appear natural in order to rationalize social injustice' (Senehi 2002, 53), which would more closely align with the concept of destructive storytelling. 


\section{Conclusion}

This paper sets out the rationale for storytelling as a process to 'deal with the past', one that is directed towards reconciliation and transformation in societies emerging from conflict. Despite some identifiable limitations and concerns, storytelling has been largely endorsed as an effective and essential element towards any peaceful resettlement in differing global, post-conflict contexts. Storytelling has been found to raise awareness and understandings of the differing sides in any conflict and, under the right conditions, offers possibilities for empathy and shifts in perspective that can potentially reconcile divided elements of a society.

While there are many differing forms of storytelling, grassroots or community-led approaches to individual and community narratives, largely centring on testimonygiving, witnessing and poststorytelling, have grown up in opposition to the promotion of more formal and dominant narratives that may lean towards singular, stereotyped or even partisan perspectives. In relation to how narratives are mediated, the employment of film within peace-building has developed as a common output, and while numerous positive examples exist, conventional documentary film has generally been overwrought with concerns about authorship, aesthetics, sensationalism and the power imbalance in the 'voices' of those involved. More recently, the creation and rapid growth of interactive forms of documentary, drawing upon multiple disciplines, technologies and platforms, have heralded new and particular opportunities for the presentation of conflicted narratives as avenues to negotiate intergroup differences.

Specifically, the paper explored the relationship between modes of interactivity and constructive storytelling by referring to international examples of interactive documentary on post conflict situations - an area that currently would benefit from deeper conceptualisation and further research. Although not envisaged as offering a definitive answer or guide, this analysis identifies that there are clear overlaps in terms of interactive documentary offering solutions to some of the limitations raised through other forms of storytelling in post-conflict contexts. Interactive documentary naturally possesses characteristics of multi-linearity, polyvocality and a shift in textual authority, entrusting the user with agency over the co-creation of meaning, which runs counter to authoritative discourses. Issues with the facilitation of agency in the storyteller may potentially be remedied by the participatory logic inherent to many interactive documentary projects.

The experiential mode offers communities in societies emerging from conflict opportunities to interact with a range of opposing perspectives and safely to reimagine contested and segregated spaces. Additionally, the conversational mode can offer an embodied experience of narratives attached to virtual locations, whilst raising emotional, empathic and moral responses in a non-threatening manner. However significant challenges remain, particularly in relation to legal and ethical implications, due to a lack of authorial control. In participatory interactive documentary projects, users directly contributing content must accept ethical and legal obligations, which demand high levels of attention and moral sensibility to avoid damaging content being published, which could exacerbate rather than reconcile difference in highly contested situations. 
In conclusion, the answer to the question, as to whether or not interactive documentary conforms to constructive storytelling, remains complex, and one that undoubtedly requires further research, not least by exploring the impact of interactive documentary experiences on users. By using Senehi's factors, it can be seen that interactive documentary broadly contributes to the negotiation of complex and contested narratives of conflict as a unique form of constructive storytelling. Nevertheless, future interactive documentary projects on war and conflict should creatively employ progressive technologies in order to enhance the range of constructive storytelling factors, such as memory, knowledge, identity, emotion, morality, geographic space etc. thereby maximising the possibilities for reconciliatory outcomes, while simultaneously reducing the possibilities associated with destructive storytelling.

The author would like to thank Professor Cahal McLaughlin, Professor Ruth Leitch and Dr. Michelle Moloney for their advice during the development of this paper.

\section{References}

Aguiar, L. (2015) We Were There: The Women of the Maze and Long Kesh Prison: Collaborative Filmmaking in Transitional Northern Ireland, Belfast: Queen's University Belfast

Boraine, A. (1999) International Responses to the TRC, South Africa: University of Cape Town

Bruzzi, S. (2000) New Documentary: A Critical Introduction, London: Routledge

Cohen, H. (2012) 'Database Documentary: From Authorship to Authoring in Remediated/Remixed Documentary', Culture Unbound, 4, 327-346

Dawson, G. (2005) 'Trauma, Place and the Politics of Memory: Bloody Sunday, Derry, 1972-2004', History Workshop Journal, Spring 59, 151-178

De la Peña, N., Weil, P., Llobera, J., Giannopoulos, E., Pompés, A., Spanlang, B., Friedman, D., Sanchez-Vivez, M. V., \& Slater, M. (2010) Immersive Journalism: Immersive Virtual Reality for the First-Person Experience of News, Presence: Teleoperators and Virtual Environments, 19(4), 291-301

De Lusenet, Y. (2007) 'Tending the garden or harvesting the fields: Digital preservation and the UNESCO charter on the preservation of the digital heritage', Library Trends, 56(1), 164-182

Dovey, J., \& Kennedy, H. (2006) Game Cultures, Maidenhead: Open University Press 
Dovey, J., \& Rose, M. (2013) 'This great mapping of ourselves - New documentary forms online', in B. Winston (ed), The Documentary Film Book, London: British Film Institute

Felman, S., \& Laub, D. (1992) Testimony: Crisis of Witnessing in Literature, Psychoanalysis, and History, New York: Routledge

Galloway, D., Mcalpine, K. B., \& Harris, P. (2007) 'From Michael Moore to JFK Reloaded: Towards a Working Model of Interactive Documentary', Journal of Media Practice 8 (3), 325-339

Gaudenzi, S. (2013) The Living Documentary: from representing reality to cocreating reality in digital interactive documentary, London: University of London, Centre for Cultural Studies of Goldsmiths

Gormally, B., \& McEvoy, K. (2009) Dealing with the past in Northern Ireland 'From below': An evaluation, The Community Foundation for Northern Ireland, Justice Associates

Hackett, C., \& Rolston, B. (2009) 'The burden of memory: Victims, storytelling and resistance in Northern Ireland', Memory Studies, 2(3), 355-376

Henderson, M. (1996) The Forgiveness Factor: Stories of Hope in a World of Conflict. London: Grosvenor

Jelin, E. (2003) State, Repression and the Labours of Memory. Minneapolis: University of Minnesota Press

Kinnick, K., Krugman, D., \& Cameron, G. T. (1996) 'Compassion fatigue: Communication and burnout toward social problems, Journalism and Mass Communication Quarterly, 73, 687-707

Lederach, J. P. (2005) The Moral Imagination: The Art and Soul of Building Peace, Oxford and New York: Oxford University Press

Mairs, J., \& McLaughlin, C. (2012) 'Unheard Voices: Recording Stories from the Troubles', in C. Mackeogh and D. O'Connell (eds), Documentary in a Changing State: Ireland Since the 1990s, Cork: Cork University Press

Mairs, J. (2013) Audiovisual Storytelling in Post-Conflict Northern Ireland: participant and audience responses to filming, editing and exhibiting memories of the Troubles via two practice-led collaborative documentary film productions, Belfast: University of Ulster

McAdams, D.P. (1993) The Stories We Live By, New York: The Guilford Press

McKee, R. (1997) Story, New York: Harper Collins 
McLaughlin, C (2010) Recording Memories from Political Conflict: A Filmmakers Journey, Bristol: Intellect

Moloney, M. (2014) Reaching out from the Archive: the role of community oral history archives in conflict transformation in Northern Ireland, Belfast: University of Ulster

Nash, K. (2012) 'Modes of Interactivity: Analysing the Webdoc', Media, Culture \& Society, 34(2), 195-210

Nash, K. (2014) 'An Interview with Ingrid Kopp, Director of Digital Initiatives Tribeca Film Institute', in K. Nash, C. Hight and C. Summerhayes (eds), New Documentary Ecologies: Emerging Platforms, Practices and Discourses. Basingstoke: Palgrave Macmillan

O'Flynn, S. (2012) ‘Documentary's Metamorphic Form: Webdoc, Interactive, Transmedia, Participatory and Beyond', Studies in Documentary Film, 6(2), 141-157

O'Neill, S., \& Nicholson-Cole, S. (2009) "Fear won't do it": Promoting positive engagement with climate change through visual and iconic representations, Science Communication, 30(3), 355

Rodgers, K. L., Leydesdorff., Dawson, G. (eds.) (2004) Trauma: Life Stories of Survivors, New Brunswick: Transaction Publishers

Senehi, J. (2002) 'Constructive Storytelling: A Peace Process', Peace and Conflict Studies, 9:2(3), 41-63

Smith, B. H. (1981) 'Narrative Version, Narrative Theories', in W. J. T. Mitchell (ed) On Narrative, Chicago: University of Chicago Press

The Consultative Group on the Past (2009) The Report of the Consultative Group on the Past, Available at http://cain.ulst.ac.uk/victims/docs/consultative group/cgp 230109 report.p df Accessed 10 May 2015

Toome, E. (2012) 'Filling wounds with salt': the pathologisation of trauma in Timor-Leste, D. Grenfell (ed) in Traversing customary community and modern nation-formation in Timor-Leste, Local-Global journal,11, 24-30

Tutu, D. (2003) Foreword. In Reconciliation After Violent Conflict: A Handbook (eds D., Bloomfield, T., Barnes and L., Huyse) Stockholm, International Institute for Democracy and Electoral Assistance

Underberg, N., \& Zorn, E. (2013) Digital Ethnography: anthropology, narrative and new media, Austin: University of Texas Press

Willis, J. (2003) The Human Journalist: Reporters, perspectives and emotions, Santa Barbara: Praegar Publishers 


\section{Filmography}

Unconstitutional about Guantánamo. Dir. Nonny de la Peña. 2004. Documentary Film

\section{Digital Works}

18 Days in Egypt. Dir. Jigar Mehta and Yasmin Elayat. 2011. Interactive Documentary

Gaza/Sderot. Dir. Susanna Lotz, Jöel Ronez and Alex Szalat. 2008. Arté. Interactive Documentary.

Gone Gitmo. Dir. Nonny de la Peña. 2007. Interactive Documentary/lmmersive Journalism.

Project Syria. Dir. Nonny de la Peña. 2014. Interactive Documentary/Immersive Journalism.

Streets of Belfast. 2015. Kabosh. Mobile App

Use of Force. Dir. Nonny de la Peña. 2013. Interactive Documentary/Immersive Journalism

Jamie McRoberts is a PhD candidate in Film Studies at Queen's University Belfast. His practice-based doctoral research examines the emerging form of digital interactive documentary, particularly in its use to negotiate contested narratives in societies emerging from violence. Jamie is a researcher for the Prisons Memory Archive, and director of $\mathrm{Maze}^{3}$ a forthcoming interactive documentary that offers a first-person immersive experience of the Maze \& Long Kesh Prison.

Email: jmcroberts04@qub.ac.uk 